\title{
Nature and Nurture Predispose to Violent Behavior: Serotonergic Genes and Adverse Childhood Environment
}

\author{
Andreas Reif*, , Michael Rösler², Christine M Freitag ${ }^{3}$, Marc Schneider², Andrea Eujen', Christian \\ Kissling ${ }^{4}$, Denise Wenzler ${ }^{2}$, Christian P Jacob', Petra Retz-Junginger', Johannes Thome ${ }^{4}$, Klaus-Peter Lesch' \\ and Wolfgang Retz ${ }^{2}$
}

'Clinical and Molecular Psychobiology, Department of Psychiatry and Psychotherapy, University of Würzburg, Würzburg, Germany; ${ }^{2}$ Institute for Forensic Psychology and Psychiatry, University of the Saarland, Homburg, Germany; ${ }^{3}$ Department of Child and Adolescent Psychiatry, University of the Saarland, Homburg, Germany; ${ }^{4}$ Department for Psychiatry, The School of Medicine, University of Wales, Swansea, UK

\begin{abstract}
Aggressive behavior is influenced by variation in genes of the serotonergic circuitry and early-life experience alike. The present study aimed at investigating the contribution of polymorphisms shown to moderate transcription of two genes involved in serotonergic neurotransmission (serotonin transporter, $5 \mathrm{HTT}$, and monoamine oxidase A, MAOA) to the development of violence and to test for gene-environment interactions relating to adverse childhood environment. A cohort of 184 adult male volunteers referred for forensic assessment participated in the study. Each individual was assigned to either a violent or a nonviolent group. Logistic regression was performed and the best-fitting model, with a predictive power of 74\%, revealed independent effects of adverse childhood environment and MAOA genotype. High environmental adversity during childhood was associated significantly with violent behavior. Forty-five percent of violent, but only $30 \%$ of nonviolent individuals carried the low-activity, short MAOA allele. Most interestingly, an interaction effect between childhood environment and 5HTT genotype on violent behavior was found in that high adversity during childhood impacted only the later-life violence if the short promoter alleles were present. These findings indicate complex interactions between genetic variation of the serotonergic circuitry and environmental factors arguing against simplistic, mono-causal explanations of violent behavior. Neuropsychopharmacology (2007) 32, 2375-2383; doi: I 0. I 038/sj.npp. I 30 I 359; published online 7 March 2007
\end{abstract}

Keywords: violence; aggression; criminality; personality; monoamine metabolism; serotonin transporter

\section{INTRODUCTION}

Aggression comprises heterogeneous neurobiological features and phenomenology. In consideration of apparently qualitative subtypes of aggression, a sensible construct was made in hypothesizing a dichotomy between an impulsivereactive-hostile-affective subtype (defensive aggression) and a controlled-proactive-instrumental-predatory subtype (offensive aggression) (Vitiello and Stoff, 1997). Although most neurobiological studies of aggression and violence unfortunately do not differentiate between defensive and offensive aggression, this distinction may be relevant in understanding the neurobiological underpinnings of aggressive behaviors, even more so they are influenced by anatomically and functionally distinct neural circuits (Lesch and Merschdorf, 2000). It is believed that the propensity for

\footnotetext{
* Correspondence: Dr A Reif, Clinical and Molecular Psychobiology, Department of Psychiatry and Psychotherapy, University of Würzburg, Füchsleinstr. 15, D-97080 Würzburg, Germany, Tel: +49931 201 76000, Fax: + 49 931 201 77550, E-mail: a.reifgmx.net Received 19 June 2006; revised 10 January 2007; accepted 15 January 2007
}

impulsive aggression, which is relatively unplanned and spontaneous but often culminates in physical violence, is associated with a low threshold for activating negative affect and with a failure to respond appropriately to the anticipated harmful consequences of behaving aggressively. Socio-psychological research underscores the relation between cognition, emotion, and aggression; negative affect such as fear and anxiety frequently precipitates, accentuates, and modulates aggressive behavior. Thus, it appears reasonable that neural circuitries that affect emotional states, like the central serotonergic system, also affect the predisposition towards aggressive behaviors.

Not only the genetic make-up, but environmental factors also influence human behavior. It is well known that earlychildhood environment also influences the later-life predisposition toward violent behaviors. Longitudinal studies assessing the development of psychopathology have replicated the strong influence of adverse parental rearing on externalizing and aggressive behavior in children (Blanz et al, 1991; Deater-Deckard et al, 1998; Fergusson et al, 1996). Oppositional and aggressive behavior in childhood is predictive of according offensive, aggressive and antisocial behavior in adulthood (August et al, 1999; Barkley et al, 2004; 
Lahey et al, 2005) as are adverse family circumstances like childhood maltreatment (Fergusson and Lynskey, 1997).

Gene-environment interactions in the development of aggressive behavior were demonstrated for child maltreatment and the monoamine oxidase A (MAOA) gene (Caspi et al, 2002; Foley et al, 2004; Huang et al, 2004). MAO-A degrades monoamine neurotransmitters thus terminating their availability. A repeat length polymorphism (MAOAuVNTR (MAOA-variable number of tandem repeats)) in the promoter region consisting of a 30-bp repeat element with 3, 3.5, 4, 5 or (rare) 6 copies was described (Sabol et al, 1998). The 3-repeat allele results in significantly decreased expression of MAO-A as compared to longer alleles (Deckert et al, 1999); the latter also resulting in higher cerebrospinal fluid (CSF) homovanillic acid levels, arguing for functional metabolic consequences of this polymorphism (Zalsman et al, 2005). For association studies, hence, MAOA-uVNTR has been dichotomized in short low-activity (3-allele) and long high-activity (3.5, 4, 5-allele) variants.

First evidence for an involvement of MAO-A in aggression came from two different lines of evidence: in a large kindred, a rare stop mutation of $M A O A$ co-segregated with aggressive behaviors in affected males (Brunner et al, 1993). Likewise, mice with a targeted deletion of MAOA show significantly increased aggressive behavior in several paradigms (Cases et al, 1995). Following the discovery of functional MAOA variants, the impact of these polymorphisms on human aggression and related behaviors was investigated. Initial studies (Samochowiec et al, 1999; Schmidt et al, 2000) argued that antisocial personality disorder in alcoholism was connected to the low-expression genotype, although this was not replicated in two rather small studies (Koller et al, 2003; $\mathrm{Lu}$ et al, 2003). Convincing evidence, however, supports the notion that MAOA-uVNTR regulates aggression and impulsivity in a gene-environment-dependent manner. A pilot study on 110 healthy males demonstrated an association of short MAOA-uVNTR alleles with lower levels on a composite measure of aggression and impulsivity (Manuck et al, 2000). Data from the Dunedin longitudinal study (Caspi et al, 2002) suggested that childhood maltreatment is a risk factor for conduct disorder, antisocial personality disorder, and disposition toward as well as execution of violence. High MAO-A activity, that is, long MAOA-uVNTR alleles, protected against this in the presence of childhood maltreatment or, conversely, short MAOA-uVNTR alleles predisposed toward violent behavior in the case of maltreatment only. Likewise, low-activity $M A O A$ alleles could be found more often in conduct disorder exclusively in the presence of adverse childhood environment (Foley et al, 2004). A Swedish study (Nilsson et al, 2006) recently demonstrated that the short MAOA-uVNTR allele interacted with adverse psychosocial risk factors during adolescence to result in criminal behavior in general, but also specifically with violence. Conflicting with some of these findings, short MAOA-uVNTR alleles in turn appear to be associated with a history of childhood abuse and with higher impulsivity measures, but not with Brown-Goodwin Aggression Scale scores (Huang et al, 2004). A further study failed to replicate the Dunedin findings, although there was a nonsignificant trend (Haberstick et al, 2005). Analogous to humans, rhesus monkeys - which feature a polymorphic VNTR in their MAOA regulatory region as well (Wendland et al,
2006) - show higher aggression levels in the presence of low-activity alleles, however, this was significant only when monkeys were mother- and not peer-reared (Newman et al, 2005).

The serotonin transporter (5HTT) is the key molecule in regulating the availability of synaptic serotonin and thus crucially balances serotonergic tone. In subjects displaying impulsive, offensive aggression, 5HTT availability is significantly reduced in the anterior cingulate cortex arguing for a role of 5HTT in violent behaviors (Frankle et al, 2005). Most interestingly, mice lacking 5HTT feature lower levels of aggression, further underscoring this notion (Holmes et al, 2002). A length variation of a repeat in the transcriptional control region of the 5HTT gene serotonin transporter repeat length polymorphism (5HTTLPR) regulates expression and serotonin (5HT) uptake, with short alleles (s, as opposed to long, l) resulting in lower transcriptional activity and consequently decreased reuptake of the transmitter. The polymorphism has been shown to be associated with neuroticism (Lesch et al, 1996) especially in patients with cluster $\mathrm{C}$ personality disorders (Jacob et al, 2004) and, in a gene-environment-dependent manner, with depression (Caspi et al, 2003). Despite the vast literature on the connection between serotonin and aggression (Lesch and Merschdorf, 2000), studies investigating the role of 5HTTLPR genotype on offensive aggression remain sparse. In heroin addicts, the s/s genotype was associated with violent offence, but not Buss-Durkee Hostility Inventory scores (Gerra et al, 2004). Additional data also pointed toward an association of the s/s genotype with violent crime (Liao et al, 2004), and a study from our group demonstrated that the $s$ allele was found significantly more often in violent-crime offenders especially when attention deficit/hyperactivity disorder (ADHD) psychopathology was present, explaining 5\% of the genetic variance of violent behavior (Retz et al, 2004).

The dopamine transporter (DAT) regulates dopaminergic tone and is another candidate gene for neuropsychiatric disorders. A VNTR in the $3^{\prime}$-untranslated region of DAT has been suggested to influence DAT mRNA stability (Michelhaugh et al, 2001), expression (Fuke et al, 2001), as well as transporter availability as assessed by single photon emission computed tomography (SPECT) imaging (van Dyck et al, 2005). No study on the interaction of this genetic variant with adverse family environment on aggressive and violent behavior in adulthood has been carried out to date. As $M A O A$ and $5 H T T$ have repeatedly been associated with aggressive behaviors, we sought to examine whether MAOAuVNTR, 5HTTLPR, and DAT alone or in combination are associated with violent criminality in imprisoned subjects. Furthermore, the impact of adverse childhood environment on later violent criminality and a possible interaction with these genotypes was investigated as it was previously suggested that MAOA genotype exerts its effect on violent or antisocial behavior only following childhood maltreatment.

\section{MATERIALS AND METHODS}

\section{Subjects}

A sample of 184 adult male, caucasian volunteers, referred for a forensic examination to the Institute of Forensic 
Psychiatry of the University of the Saarland by legal authorities for evaluation of legal responsibility or risk assessment, entered the study. Only subjects who gave written informed consent after explanation about scope and aim of the investigation were enrolled. Mean age was 34.1 years (SD, 11.7 years). Subjects with a diagnosis of current substance dependence, acute schizophrenia, major depression/bipolar disorder, or any other severe Axis-I diagnosis according to DSM-IV as well as mentally retarded subjects $(\mathrm{IQ}<70)$ were not included. Psychiatric lifetime diagnoses according to DSM-IV criteria comprised substance-use disorders (46.2\%), psychotic disorders (substance-induced or because of general medical conditions; under stable remission) $(8.2 \%)$, paraphilias $(4.5 \%)$, affective disorders $(2.2 \%)$, neurotic disorders and disorders of impulse control (3.8\%). Cluster B personality disorders were present in $27.2 \%$, personality disorders of Clusters $\mathrm{A}$ and $\mathrm{C}$ in $7.6 \%$ of the sample. As expected in an offender population, the educational and professional status of most of the subjects was low (special education, school dropout $13.4 \%$, junior high school $/<8$ classes $70.1 \%$, high school $/>8$ classes $16.5 \%$, completed professional training $55.5 \%$, no professional training $44.5 \%$ ) and the rate of unemployment was high (employed 39.3\%, unemployed 60.8\%). In all, $20.1 \%$ were married or lived in stable partnerships, $23.8 \%$ were divorced, and $56.1 \%$ never married.

All subjects underwent a semi-structured psychiatric interview according to the assessment and documentation in physical psychopathology (AMDP) system (AMDP, 2000) by well-trained psychiatrists, and a neurological examination. Childhood symptoms of ADHD were assessed using the German short version of the Wender Utah Rating Scale (WURS-k), current ADHD symptoms by the ADHD-SB (Retz-Junginger et al, 2003; Rösler et al, 2004). Each subject was assigned to a violent and a nonviolent group according to his policy record and current crimes based on a careful evaluation of all available documents. Violence, as an outcome variable of predisposition toward offensive aggression, was defined as an abiding 'overt and intentional physically aggressive behavior against another person' as suggested by Volavka (1999) and adopted by an expert consensus (Filley et al, 2001). By this means, only the subjects with habitual aggressive and violent behavior were included in the violent group, whereas offenders with a history of only nonviolent crimes were assigned to the nonviolent group. Subjects with no explicit preponderance of either criterion (eg, one severe violent crime) were not recruited for this study. Reliability of phenotype assessment (violent or nonviolent) between different raters (MR, WR) was tested in a subset of 25 subjects. Inter-rater reliability was 0.92 (assessed by Cohen's Kappa). Criminal offences of the participants of the study comprised homicide, physical injury, and robbery $(n=75)$, property offenses and fraud $(n=41)$, sexual offenses $(n=33)$, drug offenses $(n=12)$, and others $(n=67)$. Furthermore, DNA samples were collected from 150 male control subjects (mean age $34.0 \pm 11.4$ years) consisting of healthy blood donors from Germany; the sample was not screened for a history of psychiatric disorders, ADHD, or violent behavior and constitutes a population-based control sample. All control subjects, however, were free of any regular medication, and the study was explained to them. The study was approved by the Ethics Committee of the University of the Saarland and the University of Würzburg.

\section{Life History}

All forensic participants of the study were rated by an independent investigator (DW), who was blinded to the diagnostic status and genotype of the probands, with regard to the following criteria toward childhood (defined as $0-10$ years) environment: social status, family structure, emotional family climate, social integration, and school education. The items were graded from 0 to 2 points, with higher ratings indicating worse environment conditions (Table 1). A mean score of adverse childhood environment (childhood adverse environment index, CAEI) was calculated for each subject, giving a relative total adverse environment index of 0 (optimal childhood environment) to 2 (most adverse childhood environment).

\section{Genotyping}

Venous blood was drawn and DNA was extracted using a standard method. MAOA-uVNTR and the 5-HTTLPR were genotyped using previously published protocols (Deckert et al, 1999; Lesch et al, 1996). PCR of the DAT VNTR was carried out in a $25 \mu \mathrm{l}$ volume containing $20 \mathrm{ng}$ genomic DNA and $0.4 \mu \mathrm{M}$ primers. The amplification protocol consisted of $95^{\circ} \mathrm{C}$ for $5 \mathrm{~min}$, followed by 35 cycles of $95^{\circ} \mathrm{C}$ for $45 \mathrm{~s}, 67.5^{\circ} \mathrm{C}$ for $45 \mathrm{~s}$ and $72^{\circ} \mathrm{C}$ for $45 \mathrm{~s}$. PCR products were separated by electrophoresis on a $3 \%$ agarose gel stained with ethidium bromide and visualized by UV transillumination. Primers as well as detailed PCR conditions are available on request.

\section{Statistical Analysis}

Owing to their proposed functionality and analogous to previous studies, MAOA-uVNTR, DAT VNTR, and 5HTTLPR were assessed as dichotomized alleles: MAOA short alleles (ie 3 repeats) were compared to MAOA long alleles (ie 4 or 5 repeats). For 5HTTLPR, genotypes s/s and s/l were grouped together (group S; Lesch et al, 1996) and compared to the $1 / 1$ genotype (group L) owing to their functionality. For the DAT VNTR, genotypes $9 / 9,9 / 10$, and 9/11 were compared with genotypes $10 / 10$ and 10/11. All polymorphisms were in Hardy-Weinberg equilibrium. Forensic subjects were compared with regard to the presence or absence of violent behavior as described above. Univariate, exploratory assessment of possible confounding variables on the presence of violence (age, history of personality disorder, history of drug addiction, ADHD symptoms in childhood and at present) was performed by $\chi^{2}-, t$ - or Wilcoxon rank-sum tests. A $p$-value $<0.10$ was set as a threshold for association of violence with possible confounding variables. These confounding variables were controlled for in the stepwise logistic regression procedure performed to analyze the impact of genotypes and adverse childhood experience on violent behavior. Violent behavior was the dependent, and the dichotomized genotypes (MAO-A, DAT, 5-HTTLPR), adverse childhood experience (continuous variable) and interaction terms of genotypes as well as adverse childhood environment the independent 
Table I Standardized Assessment of Life History, of which the CAEl Score (Ranging from 0 to 2 ) is Derived

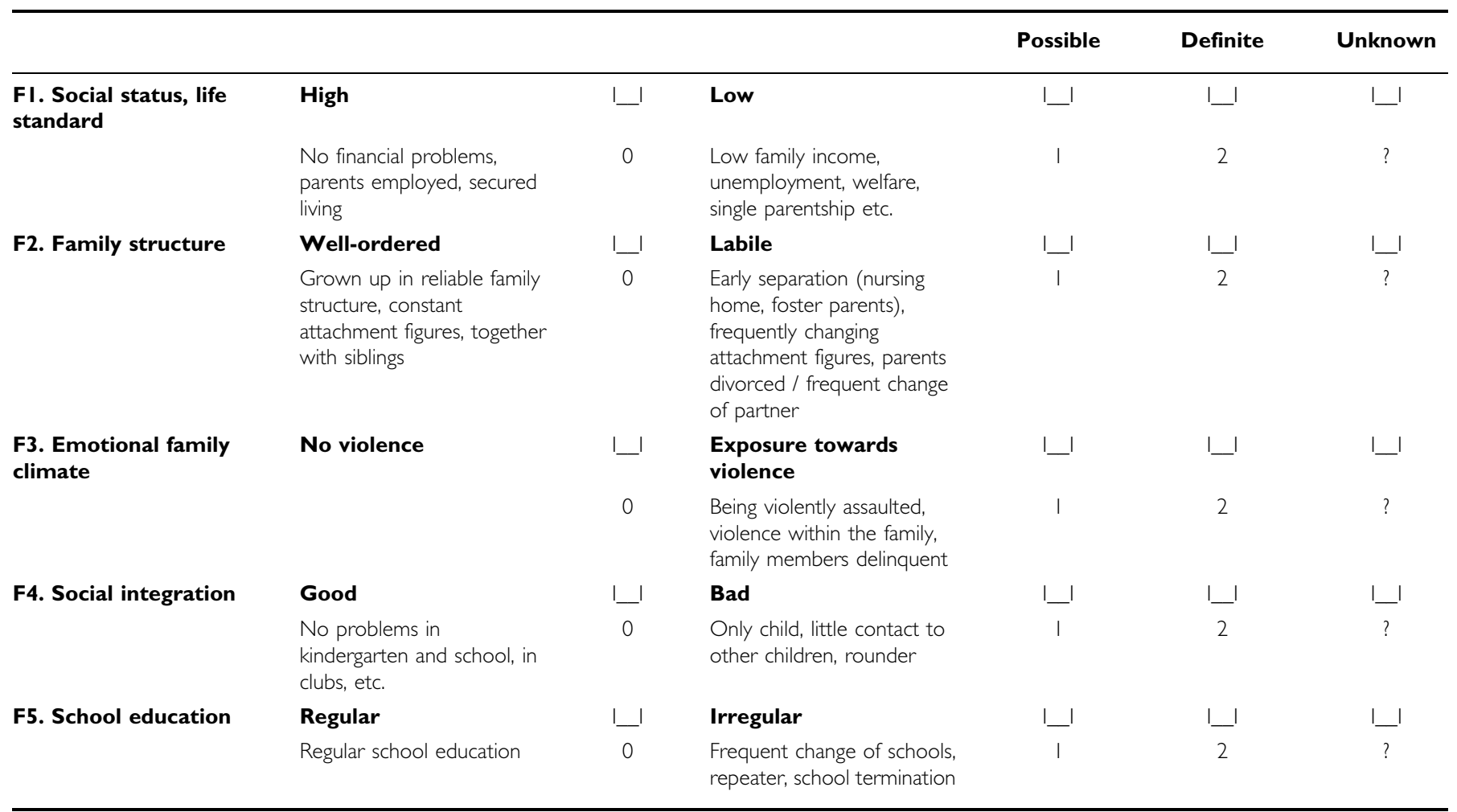

variables of interest. If an interaction term did not show an influence on the dependent variable violent behavior, it was successively taken off the model. Possible confounding variables (continuous variable age; dichotomized variables, ie presence or absence of history of personality disorder and history of drug addiction) remained in the model. The results of the final model are reported. From this model, mean cross-validation probability of violent behavior was calculated for different combinations of risk factors (dichotomized MAOA uVNTR, 5HTTLPR, and CAEI), which were compared in post hoc analyses by $\chi^{2}$ - and Wilcoxon rank-sum tests. Univariate tests were performed similarly. No adjustment of multiple testing was made as, initially, all variables were assessed in one model, and post hoc analyses were performed only on variables which had shown an effect in the logistic regression model. Statistical analyses were performed by the SAS statistical package (SAS/STAT version 8.2. SAS Institute Inc., Cary, NC, USA, 1999-2001).

\section{RESULTS}

Of the 184 subjects undergoing forensic assessment, 72 (39.1\%) had a history of recurrent violent behavior. Violent behavior was somewhat less common in older subjects (mean age violent behavior: $32.1 \pm 12.1$ years; nonviolent behavior: $35.4 \pm 11.3$ years; $t=-1.8, p=0.07)$. Individuals with a history of drug abuse were more violent (54.2\%) compared with those without a history of drug abuse (37.5\%, $\left.\chi^{2}=4.9, p=0.03\right)$. Genotype frequency, however, did not differ in individuals with history of substance abuse compared with individuals without (MAOA-uVNTR: $\chi^{2}=0.4, p=0.516 ;$ DAT: $\chi^{2}=0.0, p=0.850 ; 5$-HTTLPR: $\left.\chi^{2}=1.7,1 \mathrm{DF}, p=0.187\right)$. Personality disorders were more common in violent $(43.0 \%)$ than in nonviolent individuals $\left(29.5 \% ; \chi^{2}=3.6, p=0.06\right)$. Genotype frequency, again, did not differ in individuals with history of personality disorder compared with the individuals without (MAOA-uVNTR: $\chi^{2}=0.1, p=0.723 ;$ DAT: $\chi^{2}=0.0, p=0.851 ; 5$-HTTLPR: $\chi^{2}=0.8, p=0.383$ ). No difference in self-reported childhood or current ADHD symptoms was found between violent and nonviolent subjects. Therefore, age, history of substance abuse, and history of personality disorder were controlled for in further analyses. In 169 of the 184 individuals, complete datasets on environmental risk factors and genotypes were available.

The best-fitting model did show a predictive power of $74 \%$ and is shown in Table 2. With regard to nongenetic factors, adverse childhood environment, as assessed by the CAEI, was significantly associated with later-life violent offence. DAT did neither show an influence on violent behavior nor did it interact with $M A O A$ regarding violent behavior (interaction term 'MAO- ${ }^{\star}{ }^{\star} D A T$ ' not shown). The short alleles of $M A O A$ were associated with violent behavior $(\mathrm{OR}=2.3)$. No independent association of 5HTTLPR, genotypes with violent behavior was found, however, a strong interaction of this polymorphism with childhood environmental risk factors was elicited (Wald $\chi^{2}=6.5$, $p=0.011$ ). The interaction between MAOA-uVNTR, 5HTTLPR, and childhood environmental factors are depicted and explained in Figure 1, Tables 2 and 3. Childhood environmental risk factors did only show an influence on violent behavior in the presence of the ss and sl genotypes, 
Table 2 Association of Childhood Environment and Genetic Polymorphisms Controlled for Age, Substance Use, and Personality Disorders

\begin{tabular}{|c|c|c|c|c|}
\hline Risk factor & $\beta$-Estimate (SE) & Wald $\chi^{2}$ (I DF) & $p$-Value & Odds ratio $(95 \% \mathrm{Cl})$ \\
\hline Childhood environment & $1.42(0.45)$ & 10.2 & $p=0.001$ & $4.1(2.6-6.5)$ \\
\hline MAO-A uVNTR short allele vs long alleles & $0.82(0.37)$ & 4.9 & $p=0.027$ & $2.3(1.1-4.7)$ \\
\hline $5 H T T L P R \|$ vs sl+ss & $0.01(0.50)$ & 0.0 & $p=0.980$ & $1.0(0.6-1.6)$ \\
\hline 5HTTLPR* childhood environment & $-1.65(0.65)$ & 6.5 & $p=0.011$ & $0.2(0.1-0.4)$ \\
\hline DAT short vs long alleles & $0.54(0.35)$ & 2.3 & $p=0.127$ & $1.7(0.9-3.4)$ \\
\hline NO vs history of personality disorder & $-0.11(0.38)$ & 0.1 & $p=0.778$ & $0.9(0.4-1.9)$ \\
\hline Age & $-0.01(0.02)$ & 0.6 & $p=0.436$ & $1.0(1.0-1.0)$ \\
\hline Intercept & $-0.9(0.48)$ & 3.6 & $p=0.056$ & \\
\hline
\end{tabular}

Cl, confidence interval; DF, degree of freedom.

Test of global null hypothesis: Wald $\chi^{2}=24.9,8$ DF, $p=0.002$.

Bold values indicate significant results.

but not in the presence of ll, that is, the L genotype was protective against the influence of childhood adversity with respect to later-life violent behavior. For post hoc analyses, the CAEI was dichotomised at the cutoff of 0.4 , which represents the median value of the full sample. High CAEI, therefore, has been assumed for a CAEI $>0.4$, and low CAEI has been assumed for CAEI $\leqslant 0.4$. Mean CAEI was $0.7 \pm 0.6$ in violent, and $0.4 \pm 0.6$ in nonviolent individuals, which was significant in post hoc univariate analyses $(Z=3.0$, $p=0.003)$. This also revealed that MAO-A short alleles ( $n=31$ in 72 violent individuals $v s n=32$ in 112 nonviolent individuals) were significantly associated with violent behaviors $\left(\chi^{2}=4.1, p=0.043\right)$. When mean cross-validation probabilities were computed, carrying the short MAOA and 5HTT alleles and having been exposed to childhood environment, most strongly predicted violent behavior (Table 3).

MAOA-uVNTR, 5HTTLPR, and DAT genotypes have furthermore been determined in a population-based control sample with unknown childhood environment; all genotypes were not significantly different from the forensic sample as a whole (MAOA-uVNTR, short alleles 33\%; 5HTTLPR L group 33\%; DAT 9/9+9/10 alleles 49\%; all $p>0.1$ ) arguing that the forensic sample as a whole is genetically homogenous to its provenance population.

\section{DISCUSSION}

The major findings of the present study are (a) MAOA genotype and adverse childhood environment independently of each other increased the risk for later-life violent behavior, (b) 5HTT polymorphism was associated with violence in a gene-environment-dependent manner, ie the 1/l genotype was protective against childhood adversity, and (c) a DAT variation does not seem to play a role in the disposition toward violence.

MAOA-uVNTR has repeatedly been suggested to be involved in the regulation of impulsivity and aggression, both in primates and in humans. This regulatory polymorphism is thought to be an example of balanced selection, that is, it shifts the predisposition of its carrier either toward offensive, risk-taking behavior or toward

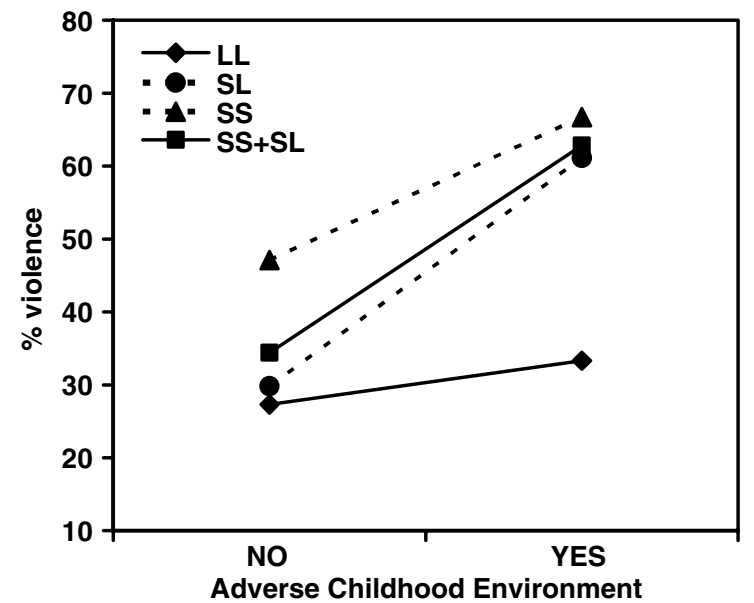

Figure I A 5HTT polymorphism is associated with violence in a geneenvironment interaction manner. Subjects were stratified for the presence or absence of adverse childhood environment; the cutoff was 0.4 according to the median adverse environment score. Probands which were homozygous for long alleles were less prone to commit violent crime as opposed to heterozygous and homozygous short-allele carriers. In homozygous long allele carriers, adverse childhood environment did not increase violent behavior, whereas in homozygous and even more so in heterozygous short-allele carriers, adverse childhood environment did significantly increase the rate of violent behavior indicating a geneenvironment interaction of $5 \mathrm{HTTLPR}$.

defensive subordination. Obviously, both of these opposites have evolutionary advantages as well as disadvantages leading to the preservation of respective 'risk' alleles. Given that the effects of MAOA-uVNTR rely on this polymorphism and not other genetic variations, it appears to be a forceful moderator of aggressive behaviors. This influence was suggested to depend on environmental factors: especially when adverse childhood conditions exist, short MAOA-uVNTR alleles may increase the risk for higher childhood (Foley et al, 2004) as well as later-life (Caspi et al, 2002; Huang et al, 2004) aggression and impulsivity. Contrasting these investigations, we found that MAOA genotype independently of childhood experiences, increased the risk to commit violent crime. Likewise, Haberstick et al (2005) found no interaction of MAOA and 
Table 3 Mean Probabilities for Presence of Violence According to Logistic Regression Model in Eight Different Risk Groups

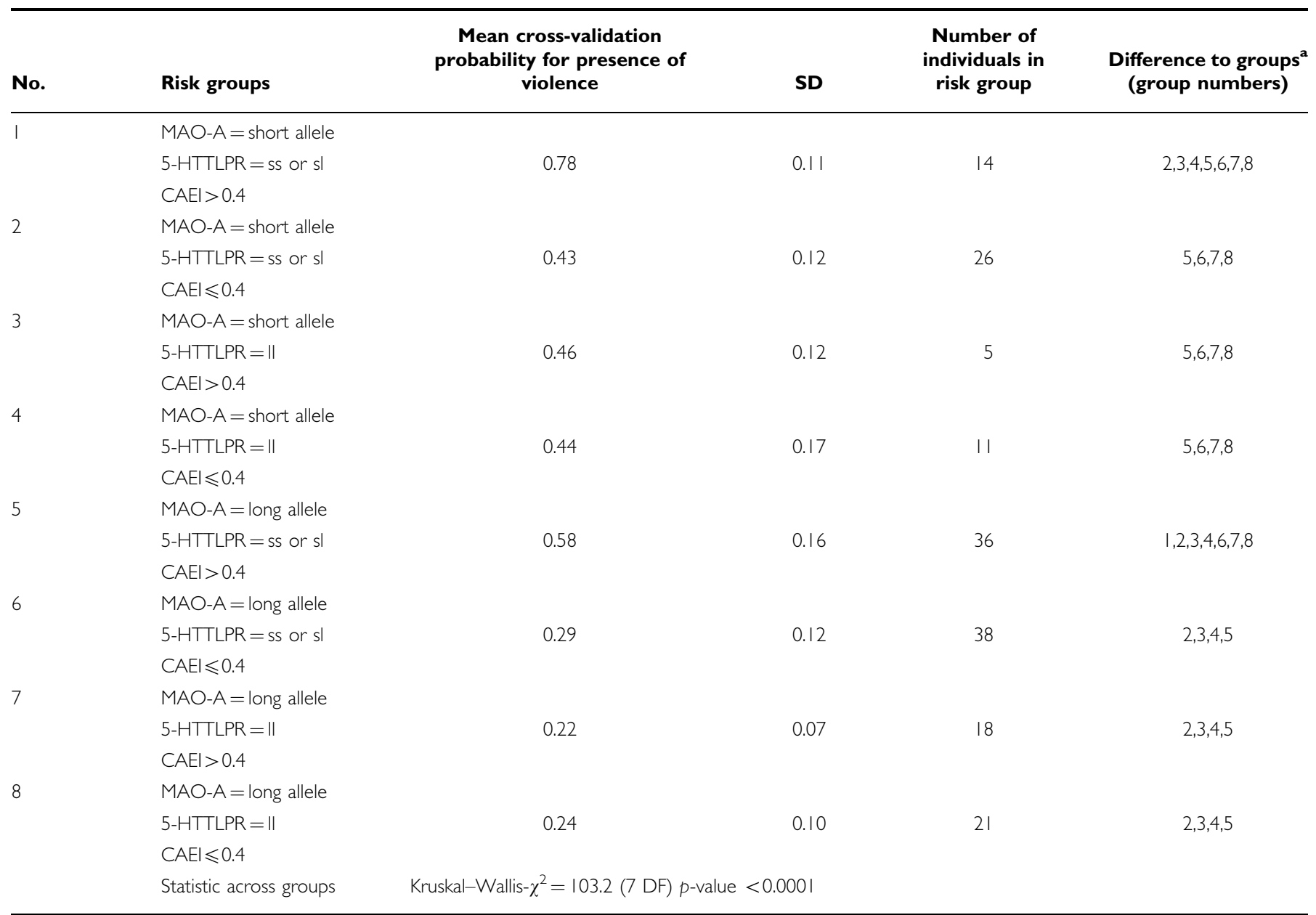

CAEl, childhood adverse environment index; SD, standard deviation of the mean.

A cross validation probability of I would fully predict violent behavior, whereas a probability of 0 would fully predict no violent behavior.

${ }^{a}$ Difference assessed by Wilcoxon two-sample test; criterium $p<0.05$.

childhood maltreatment, but also no effect of $M A O A$ genotype alone on a composite index of antisocial behavior. Explanations for these discrepant findings are manifold: first, our main outcome variable is habitual violent behavior. Antisocial behavior or conduct disorder include these but also a number of other behaviors, thus being a much broader defined measure with a corresponding loss of discriminatory power. Likewise, impulsivity scores and related questionnaires differ from our categorical division. Moreover, impulsivity and aggression are distinct behaviors which share neurobiological mechanisms only partially. A further difference is the assessment of childhood environment. Our study has the disadvantage of retrospective data collection and bases presumably on self-report rather than on established adversity measures. However, the finding that our adversity score was associated with violent crime - in accordance with most other studies related to this topic - argues for the construct validity of this score.

Another study (Nilsson et al, 2006) also demonstrated that both criminal behavior in general as well as violence were influenced by MAOA genotype only in the presence of psychosocial risk factors (maltreatment and living in a multi-family house). Comparing this to our study, we investigated a wider range of risk factors; furthermore, the number of subjects in each class was relatively small in the Swedish study, which dealt exclusively with adolescents. Violent behavior observed during puberty might constitute something different than abiding violent behavior in adulthood; furthermore, it is well known that genetic influences become more important with increasing age which may, in part, explain the contrasting findings.

Apart from these methodological differences, data suggesting an interaction of $M A O A$ genotype with environment is not so consistent as it seems at first. The study by Huang et al (2004) demonstrated an association of MAOA-uVNTR with the experience of childhood abuse (not evident in other studies (Caspi et al, 2002; Haberstick et al, 2005)) relying on a small number of subjects and, likewise, their finding on increased BIS scores in maltreated MAOA short allele carriers is of borderline significance and based on few subjects ( $n=26$ and 18, respectively). Similarly, Foley et al (2004) reported that short MAOA-uVNTR alleles result in conduct disorder in interaction with exposure to lifetime adversities. This finding derived mainly from those subjects having three or four lifetime adversities, comprising 20 subjects, six of which having the short MAOA allele, and 
four of which were suffering from conduct disorder. At this extreme end of the scale, gene-environment interaction may be present although not evident in our sample. In a sub-analysis of the study by Caspi et al (2002), conviction for violence was examined allowing comparison with our findings; again, the finding on a gene-environment interaction resulted from approximately 15 subjects convicted in the short $M A O A$ allele group with childhood maltreatment (from a total of 55 in this group). Thus, owing to this relatively small sample size, we agree with the authors that these findings need to be considered as preliminary.

Despite the limitations of the present study, that is, retrospective assessment of childhood environment, its major advance is that a higher number of subjects of the main outcome variable, that is, violence $(n=72)$, was examined as compared to previous studies, increasing the power to detect gene-environment interactions. In our sample, presence of the short MAOA allele neither predisposed to a more adverse childhood environment, nor did it exert its influence only under certain and given environmental conditions. Thus, carrying a short allele of the MAOA-uVNTR acted as a true and independent risk factor for later-life aggression, further adding to the risk conveyed by childhood maltreatment. Work from our group has previously shown that not only aggression, but also other domains of disruptive, outward-bound behavioral traits seem to be under partial genetic influence of MAOA$\mathrm{uVNTR}$ (Jacob et al, 2005). Individuals with cluster B, but not cluster $\mathrm{C}$ personality disorders carried short alleles more frequently, that is, MAO-A seems to play a regulatory role in the control of socially 'inappropriate' out-acting behavior.

A recent $\mathrm{fMRI}$ study shed some light on possible neurobiological underpinnings of MAOA genotype on aggressive behavior, demonstrating that the at-risk genotype results in amygdalar hyperreactivity in response to emotional arousal, paralleled by impaired response of prefrontal brain regions including the anterior cingulate cortex (Meyer-Lindenberg et al, 2006). Considering the data on reduced 5HTT availability in this structure in aggressive subjects (Frankle et al, 2005), serotonin metabolism in the cingulate gyrus seems to be a crucial determinant of disposition toward violent behavior. Accordingly, 5HTT constitutes another candidate gene for violent behavior. A small, yet increasing number of studies also investigated the implications of 5HTT genotype on aggression and demonstrated an association between short 5HTT alleles and violent behavior (Gerra et al, 2004; Retz et al, 2004; Liao et al, 2004), although the latter study conveyed several problems as the polymorphism was not in Hardy-Weinberg equilibrium. Gene-environment interactions have not yet been examined in humans. Here we show that homozygotes for the long allele are generally less likely to develop laterlife aggressive behavior, whereas short allele homozygotes behave the opposite way. Most interestingly, only heterozygotes were influenced by environmental factors, that is, this polymorphism might have a role in balancing aggressive behaviors in differing societies. Corresponding to this finding, in rhesus monkeys adverse early environment interacted with the monkey analogue of the 5HTTLPR in exactly the same manner as in the present study (Barr et al, 2003), arguing further for the notion that this polymorphism modulates the response toward adverse environments.

As behavioral traits are quantitative, they are influenced not only by one, but many interacting genes. A sensible rationale to search for epistasis is to investigate gene networks, where several genes interact functionally. Thus, we tested for but failed to detect an interaction of a presumably regulatory DAT polymorphism with MAOAuVNTR - neither with respect to violence, delinquency, nor ADHD. Also considered independently, the DAT polymorphism did not seem to convey any risk toward any of these traits. Taken together, this suggests that serotonin degradation by MAO-A is the major moderator pathway influencing violent behavior, but not dopamine metabolism. With regard to aggression, DAT genotype has not previously been tested. However, our findings are in line with work in nonhuman primates (Wendland et al, 2005) showing that MAOA as well as 5HTT, but not DAT polymorphisms influence predisposition toward aggressive behavior.

No matter whether the genetic association of MAOAuVNTR and 5HTTLPR with violent crime proves true in replication attempts or not, this does not make a case for an individual being exculpated by his genetic make-up. As opposed to rare cases of deleterious mutations resulting in severe mental disorder, common polymorphisms such as MAOA-uVNTR convey only a statistical predisposition toward a certain behavior. This is proven by the fact that ca. $30 \%$ of all males carry short MAOA-uVNTR alleles and are not acting violently. Although many lines of evidence indicate that common polymorphisms act probabilistic rather than deterministic (see also Kendler, 2006 for a thoughtful review on this topic), molecular genetic studies on the neurobiology of aggression and violence are, nevertheless, interesting not only for neuroscientists but also for policymakers and legislators in order to acknowledge gene-environment effects and to create environments protecting against violent behaviors.

\section{ACKNOWLEDGEMENTS}

We are indebted to $\mathrm{T}$ Töpner for excellent technical assistance. This study was supported by the Deutsche Forschungsgemeinschaft (Grant RE1632/1-1 and 1-3 to AR, KFO $125 / 1-1$ to AR and K-PL, and SFB581 to K-PL), Bundesministerium für Bildung, Wissenschaft, Forschung und Technologie (IZKF Würzburg, 01KS9603 to K-PL) and the European Commission (NEWMOOD LSHM-CT-2003503474 to K-PL).

\section{CONFLICT OF INTEREST}

The authors report no conflict of interest.

\section{REFERENCES}

Arbeitsgemeinschaft für Methodik und Dokumentation in der Psychiatrie (AMDP) (2000). Das AMDP-System. Manual zur Dokumentation Psychiatrischer Befunde. Hogrefe: Göttingen. 
August GJ, Realmuto GM, Joyce T, Hektner JM (1999). Persistence and desistance of oppositional defiant disorder in a community sample of children with ADHD. J Am Acad Child Adolesc Psychiatry 38: 1262-1270.

Barkley RA, Fischer M, Smallish L, Fletcher K (2004). Young adult follow-up of hyperactive children: antisocial activities and drug use. J Child Psychol Psychiatry 45: 195-211.

Barr CS, Newman TK, Becker ML, Parker CC, Champoux M, Lesch K-P et al (2003). The utility of the non-human primate; model for studying gene by environment interactions in behavioral research. Genes Brain Behav 2: 336-340.

Blanz B, Schmidt MH, Esser G (1991). Familial adversities and child psychiatric disorders. J Child Psychol Psychiatry 32: 939-950.

Brunner HG, Nelen M, Breakefield XO, Ropers HH, van Oost BA (1993). Abnormal behavior associated with a point mutation in the structural gene for monoamine oxidase A. Science 262: 578-580.

Cases O, Seif I, Grimsby J, Gaspar P, Chen K, Pournin S et al (1995). Aggressive behavior and altered amounts of brain serotonin and norepinephrine in mice lacking MAOA. Science 268: $1763-1766$.

Caspi A, McClay J, Moffitt TE, Mill J, Martin J, Craig IW et al (2002). Role of genotype in the cycle of violence in maltreated children. Science 297: 851-854.

Caspi A, Sugden K, Moffitt TE, Taylor A, Craig IW, Harrington H et al (2003). Influence of life stress on depression: moderation by a polymorphism in the 5-HTT gene. Science 301: 386-389.

Deater-Deckard K, Dodge KA, Bates JE, Pettit GS (1998). Multiple risk factors in the development of externalizing behavior problems: group and individual differences. Dev Psychopathol 10: $469-493$.

Deckert J, Catalano M, Syagailo YV, Bosi M, Okladnova O, Di Bella $\mathrm{D}$ et al (1999). Excess of high activity monoamine oxidase A gene promoter alleles in female patients with panic disorder. Hum Mol Genet 8: 621-624.

Fergusson DM, Horwood LJ, Lynskey MT (1996). Childhood sexual abuse and psychiatric disorder in young adulthood: II. Psychiatric outcomes of childhood sexual abuse. J Am Acad Child Adolesc Psychiatry 35: 1365-1374.

Fergusson DM, Lynskey MT (1997). Physical punishment/maltreatment during childhood and adjustment in young adulthood. Child Abuse Negl 21: 617-630.

Filley CM, Price BH, Nell V, Antoinette T, Morgan AS, Bresnahan JF et al (2001). Toward an understanding of violence: neurobehavioral aspects of unwarranted physical aggression: Aspen Neurobehavioral Conference consensus statement. Neuropsychiatry Neuropsychol Behav Neurol 14: 1-14.

Foley DL, Eaves LJ, Wormley B, Silberg JL, Maes HH, Kuhn J et al (2004). Childhood adversity, monoamine oxidase a genotype, and risk for conduct disorder. Arch Gen Psychiatry 61: 738-744

Frankle WG, Lombardo I, New AS, Goodman M, Talbot PS, Huang $\mathrm{Y}$ et al (2005). Brain serotonin transporter distribution in subjects with impulsive aggressivity: a positron emission study with [11C]McN 5652. Am J Psychiatry 162: 915-923.

Fuke S, Suo S, Takahashi N, Koike H, Sasagawa N, Ishiura S (2001). The VNTR polymorphism of the human dopamine transporter (DAT1) gene affects gene expression. Pharmacogenomics $J$ 1: $152-156$.

Gerra G, Garofano L, Santoro G, Bosari S, Pellegrini C, Zaimovic A et al (2004). Association between low-activity serotonin transporter genotype and heroin dependence: behavioral and personality correlates. Am J Med Genet B Neuropsychiatr Genet 126: $37-42$.

Haberstick BC, Lessem JM, Hopfer CJ, Smolen A, Ehringer MA, Timberlake D et al (2005). Monoamine oxidase A (MAOA) and antisocial behaviors in the presence of childhood and adolescent maltreatment. Am J Med Genet B Neuropsychiatr Genet 135 59-64.

Holmes A, Murphy DL, Crawley JN (2002). Reduced aggression in mice lacking the serotonin transporter. Psychopharmacology (Berlin) 161: 160-167.

Huang YY, Cate SP, Battistuzzi C, Oquendo MA, Brent D, Mann JJ (2004). An association between a functional polymorphism in the monoamine oxidase a gene promoter, impulsive traits and early abuse experiences. Neuropsychopharmacology 29: 1498-1505.

Jacob CP, Muller J, Schmidt M, Hohenberger K, Gutknecht L, Reif A et al (2005). Cluster B personality disorders are associated with allelic variation of monoamine oxidase A activity. Neuropsychopharmacology 30: 1711-1718.

Jacob CP, Strobel A, Hohenberger K, Ringel T, Gutknecht L, Reif A et al (2004). Association between allelic variation of serotonin transporter function and neuroticism in anxious cluster $\mathrm{C}$ personality disorders. Am J Psychiatry 161: 569-572.

Kendler KS (2006). Reflections on the relationship between psychiatric genetics and psychiatric nosology. Am J Psychiatry 163: $1138-1146$.

Koller G, Bondy B, Preuss UW, Bottlender M, Soyka M (2003). No association between a polymorphism in the promoter region of the MAOA gene with antisocial personality traits in alcoholics. Alcohol Alcohol 38: 31-34.

Lahey BB, Loeber R, Burke JD, Applegate B (2005). Predicting future antisocial personality disorder in males from a clinical assessment in childhood. J Consult Clin Psychol 73: 389-399.

Lesch K-P, Bengel D, Heils A, Sabol SZ, Greenberg BD, Petri S et al (1996). Association of anxiety-related traits with a polymorphism in the serotonin transporter gene regulatory region. Science 274: 1527-1531.

Lesch K-P, Merschdorf U (2000). Impulsivity, aggression, and serotonin: a molecular psychobiological perspective. Behav Sci Law 18: 581-604.

Liao DL, Hong CJ, Shih HL, Tsai SJ (2004). Possible association between serotonin transporter promoter region polymorphism and extremely violent crime in Chinese males. Neuropsychobio$\log y$ 50: 284-287.

Lu RB, Lin WW, Lee JF, Ko HC, Shih JC (2003). Neither antisocial personality disorder nor antisocial alcoholism is associated with the MAO-A gene in Han Chinese males. Alcohol Clin Exp Res 27: 889-893.

Manuck SB, Flory JD, Ferrell RE, Mann JJ, Muldoon MF (2000). A regulatory polymorphism of the monoamine oxidase-A gene may be associated with variability in aggression, impulsivity, and central nervous system serotonergic responsivity. Psychiatry Res 95: 9-23.

Meyer-Lindenberg A, Buckholtz JW, Kolachana B, Hariri AR, Pezawas L, Blasi G et al (2006). Neural mechanisms of genetic risk for impulsivity and violence in humans. Proc Natl Acad Sci USA 18: 6269-6274.

Michelhaugh SK, Fiskerstrand C, Lovejoy E, Bannon MJ, Quinn JP (2001). The dopamine transporter gene (SLC6A3) variable number of tandem repeats domain enhances transcription in dopamine neurons. J Neurochem 79: 1033-1038.

Newman TK, Syagailo YV, Barr CS, Wendland JR, Champoux M, Graessle $\mathrm{M}$ et al (2005). Monoamine oxidase A gene promoter variation and rearing experience influences aggressive behavior in rhesus monkeys. Biol Psychiatry 57: 167-172.

Nilsson KW, Sjoberg RL, Damberg M, Leppert J, Ohrvik J, Alm PO et al (2006). Role of monoamine oxidase a genotype and psychosocial factors in male adolescent criminal activity. Biol Psychiatry 59: 121-127.

Retz W, Retz-Junginger P, Supprian T, Thome J, Rosler M (2004). Association of serotonin transporter promoter gene polymorphism with violence: relation with personality disorders, 
impulsivity, and childhood ADHD psychopathology. Behav Sci Law 22: 415-425.

Retz-Junginger P, Retz W, Blocher D, Stieglitz R-D, Georg T, Supprian $\mathrm{T}$ et al (2003). Reliability and validity of the German short version of the Wender Utah Rating Scale for the retrospective assessment of attention deficit hyperactivity disorder. Nervenarzt 74: 987-993.

Rösler M, Retz W, Retz-Junginger P, Thome J, Supprian T, Nissen $\mathrm{T}$ et al (2004). Tools for the diagnosis of attention-deficit hyperactivity disorder in adults. Self-rating behaviour questionnaire und diagnostic checklist. Nervenarzt 75: 888-895.

Sabol SZ, Hu S, Hamer D (1998). A functional polymorphism in the monoamine oxidase A gene promoter. Hum Genet 103: 273-279.

Samochowiec J, Lesch K-P, Rottmann M, Smolka M, Syagailo YV, Okladnova O et al (1999). Association of a regulatory polymorphism in the promoter region of the monoamine oxidase A gene with antisocial alcoholism. Psychiatry Res 86: 67-72.

Schmidt LG, Sander T, Kuhn S, Smolka M, Rommelspacher H, Samochowiec J et al (2000). Different allele distribution of a regulatory MAOA gene promoter polymorphism in antisocial and anxious-depressive alcoholics. J Neural Transm 107: 681-689. van Dyck CH, Malison RT, Jacobsen LK, Seibyl JP, Staley JK, Laruelle $\mathrm{M}$ et al (2005). Increased dopamine transporter availability associated with the 9-repeat allele of the SLC6A3 gene. J Nucl Med 46: 745-751.

Vitiello B, Stoff DM (1997). Subtypes of aggression and their relevance to child psychiatry. J Am Acad Child Adolesc Psychiatry 36: 307-315.

Volavka J (1999). The neurobiology of violence: an update. J Neuropsychiatry Clin Neurosci 11: 307-314.

Wendland JR, Hampe M, Newman TK, Syagailo Y, Meyer J, Schempp W et al (2006). Structural variation of the monoamine oxidase A gene promoter repeat polymorphism in nonhuman primates. Genes Brain Behav 5: 40-45.

Wendland JR, Lesch K-P, Newman TK, Timme A, Gachot-Neveu $\mathrm{H}$, Thierry B et al (2005). Differential functional variability of serotonin transporter and monoamine oxidase a genes in macaque species displaying contrasting levels of aggressionrelated behavior. Behav Genet 36: 163-172.

Zalsman G, Huang YY, Harkavy-Friedman JM, Oquendo MA, Ellis SP, Mann JJ (2005). Relationship of MAO-A promoter (u-VNTR) and COMT (V158M) gene polymorphisms to CSF monoamine metabolites levels in a psychiatric sample of caucasians: a preliminary report. Am J Med Genet B Neuropsychiatr Genet 132: 100-103. 